\title{
A Model of Intertemporal Emission Trading, Banking, and Borrowing*
}

\author{
JONATHAN D. RUBIN \\ Department of Economics and Energy, Environment and Resources Center, University of
}

Tennessee, Knoxville, Tennessee 37996

Received October 30, 1995; revised N ovember 13, 1995

\begin{abstract}
This paper provides a general treatment of emission trading, banking, and borrowing in an intertemporal, continuous-time model. U sing optimal-control theory, the decentralized behavior of firms is shown to lead to the least-cost solution attainable under joint-cost minimization. Explicit solutions for the time paths of emissions and permit prices are derived when firms are allowed to both bank and borrow and when firms are only allowed to bank emission permits. The policy implications of emission banking and borrowing are discussed. (๑) 1996 A cademic Press, Inc.
\end{abstract}

\section{INTRODUCTION}

Marketable emission permits are an economic instrument used to attain a predetermined level of environmental quality. The basic concept behind emission trading, originated by $D$ ales [5], is a simple one. Initially, a regulatory agency limits the overall level of emissions, either by setting a standard or allocating emissions, and then it allows firms to trade their emission allocations or surplus permits. It is now widely agreed among economists that marketable emission permits can be a cost-effective strategy for controlling environmental pollutants, and an extensive literature on their properties has developed (see Tietenberg [12] and Cropper and 0 ates [4] for thorough reviews). This work has identified three sources of potential cost savings: emission trading between firms, emission averaging between sources within a firm, and emission trading through time. Despite common reference to these three components, previous theoretical and empirical research has focused almost exclusively on the first two items, trading and averaging.

The small amount of research into emission banking and borrowing is regrettable since public policymakers have already begun to incorporate banking and borrowing rules into law. For example, the banking (and trading) of sulfur dioxide is now authorized by the Clean A ir A ct A mendments of 1990, and California allows manufacturers of passenger cars to bank (and trade) hydrocarbon emissions. In the context of fuel efficiency, rather than emissions, the borrowing and banking of

*The author appreciates helpful comments on earlier versions of this paper from M ichael Caputo, A my F armer, Gloria H elfand, Catherine Kling and two anonymous referees. 
CAFE (corporate average fuel economy) credits for up to three years has been allowed since 1980 (Congressional Q uarterly 1980 A Imanac [2, pp. 487, 488]). ${ }^{1}$

However, the concept of marketable permits, and intertemporal trading in particular, goes far beyond the realm of environmental cleanup or fuel economy standards. It applies to the trade of goods whose existence is statutorily generated but privately transferable. For example, the concept applies to the allocation of residential or commercial property development rights or to the buying and selling of federal funds between banks who must meet reserve requirements. In the latter case, conservative banks who choose to carry surplus reserve requirements act as sellers of overnight loans (e.g., trading) and, in addition, may choose to hold additional excess reserves speculatively over several time periods (e.g., banking) in the hope that a lucrative loan opportunity arises. Throughout this paper, however, the discussion of banking will be couched in terms of standard usage within the environmental field, which refers to emission of pollutants by firms.

Within the environmental literature this paper fills the theoretical gap by providing a comprehensive treatment of intertemporal emission trading. ${ }^{2}$ In particular, it explores the problem of minimizing the cost of intertemporal emission control by $N$ heterogeneous firms in the presence of pollution standards and emission permits that are tradable across firms and through time. In such a setting, firms may directly reduce emissions, and they may purchase, sell, bank and borrow emission permits in order to meet applicable standards or to take advantage of any speculative opportunities that may arise. To generate permits, a firm may choose to pollute less than the current standard. These generated permits may be sold to a different firm or deposited in an emission bank to be used later by the firm or sold at a later time to another firm. The borrowing of permits occurs when a firm pollutes more than its current standard, but the cumulative deficit must be repaid by the end of the planning horizon. Banking and borrowing lower the cost of compliance with emission standards by allowing firms to adjust their emission stream more flexibly through time.

The model used here builds on the seminal static paper by M ontgomery [7] on marketable permits and extends the work of Tietenberg [12] and Cronshaw and Kruse [3], who examine some aspects of permit markets with banking in discrete time. Tietenberg characterizes the joint least-cost allocation of pollution for a cumulative pollutant given a constraint on the total amount of pollution over time. In this cumulative emission-permit system it appears that all permits are issued at the beginning of the time horizon. Some permits are therefore always banked until used up. Before the permits are used up their price must rise at the rate of interest. Cronshaw and Kruse examine a permit system with banking where permits are allocated to firms in each of $T$ periods. They show that in a market for transfer-

\footnotetext{
${ }^{1}$ With the borrowing of emission credits there is the obvious concern about firms borrowing and then declaring bankruptcy. In the CAFE program, enforcement of the CAFE standards takes the form of fines and a review of company product planning to determine the likelihood of future compliance (Shaffer [10]). The enforcement problem is inversely related to the cost of entry and exit. For capital-intensive industries such as electrical power producers or automobile manufacturers, enforcement should not be a problem. For industries characterized by a rapid turnover of firms, enforcement of all environmental regulations is a more serious issue.

${ }^{2}$ See Rubin and Kling [8] for an empirical examination of emission banking and borrowing for light-duty vehicle manufacturers.
} 
able and bankable permits, a competitive equilibrium exists and achieves aggregate emission targets at least system cost. Cronshaw and K ruse also show that if firms do not desire to bank, permit prices will rise by less than the rate of interest.

This paper extends the work of Tietenberg and Cronshaw and K ruse by providing a more general treatment of permit trading in continuous time through the use of optimal-control theory. Instead of limiting intertemporal trading to banking, this paper starts from the context of allowing both borrowing and banking with restrictions on borrowing as a special case. The formulation allows the derivation and extension of the results of Tietenberg and Cronshaw and Kruse, but interpretations are necessarily somewhat different. Importantly, the continuous-time framework allows for the explicit solution for the time path of emissions, which, cost savings notwithstanding, may be intertemporal emission trading's most significant aspect. N either Tietenberg's nor Cronshaw and Kruse's paper examines this issue in detail. ${ }^{3}$ In addition, this analysis extends the model of Cronshaw and Kruse by considering the qualitative impacts of emission borrowing on permit prices, the emission stream, and total social damages.

\section{THE FORMAL MODEL}

Consider a firm, $i$, that has two control variables, $e_{i}(t)$, the quantity of emissions each period, and $y_{i}(t)$, the quantity of emission permits bought $\left(y_{i}>0\right)$ or sold $\left(y_{i}<0\right)$ at price $P(t)$, which will be determined by the equilibrium conditions of all firms in the permit market over the planning horizon of length $T$. The level of emissions that are in the bank, $B_{i}(t)$, is a state variable.

Following Montgomery [7], the abatement-cost function for firm $i, C_{i}\left(e_{i}\right)$, is equal to the difference between the unconstrained profits and profits in which the firm adopts an emission level $S$ (where $S$ is less than the unconstrained emission level, $e$ ) and adjusts its output in order to obtain maximum profits for the constrained level of emissions. It is assumed that $C_{i}$ is twice continuously differentiable and convex in $e_{i}$ and that marginal abatement costs, $-C_{i}^{\prime}\left(e_{i}\right)$, are positive and strictly increasing, that is, $C_{i}^{\prime}\left(e_{i}\right)<0$ and $C_{i}^{\prime \prime}(e)>0$.

Firms choose abatement levels and permit purchases and sales given that permit prices, $P(t)$, might change over time. This makes the formal model nonautonomous. In addition, firms are assumed to be making decisions over a finite time horizon of length $T$. The length of $T$ can, of course, be relatively short or very long.

\section{THE J OINT-COST PROBLEM}

In the joint-cost problem, the regulator's goal is to minimize the total costs of pollution abatement of $N$ heterogeneous firms subject to reaching a regional emission standard, $S(t)$. The regulator assigns each firm a standard or endowment of emissions, $S_{i}(t)$, so that $\sum_{i=1}^{N} S_{i}(t)=S(t)$. Note that emission banking and

${ }^{3}$ Tietenberg [12, p. 29] notes that his cumulative-emission permit system does not regulate emission rates but only total emissions. Cronshaw and $\mathrm{K}$ ruse $[3, \mathrm{p} .6]$ note that banking could lessen environmental damages by delaying emissions or could allow firms to possibly emit large amounts of emission using previously banked permits. 
borrowing, as opposed to trading, change the nature of standards since firms can emit above the standard at some points in time. $W$ hat is required is that firms have to fulfill the cumulative standard over the entire planning horizon. In the joint-cost problem, the regulator is able to achieve cost savings by optimally adjusting the emission stream. Defining the optimal-value function as $J^{* *}, B=\sum B_{i}$ as the aggregate stock of banked emissions, $\dot{B}$ as the rate of change of aggregate banked emissions, and $T$ as the terminal time period, the problem can be written $a^{4}$

$$
\begin{gathered}
J^{* *} \equiv \underset{e_{i}}{\operatorname{Min}} \int_{0}^{T} e^{-r t} \sum_{i}^{N} C_{i}\left(e_{i}(t)\right) d t \\
\text { s.t. } \quad \dot{B}=\sum_{i=1}^{N}\left(S_{i}(t)-e_{i}(t)\right) \\
B(0)=0, \quad B(t) \geq 0 \\
e_{i}(t) \geq 0, \quad \forall i .
\end{gathered}
$$

The objective functional (1) minimizes the sum of the $N$ firms' present discounted emission-abatement costs. Equation (2) is the state equation that shows that the changes in the aggregate stock of banked emissions equal the aggregate differences between all firms' standards and emissions. The standards, $S_{i}$, can be interpreted either as firm-specific emission standards or as initial endowments of permits where the emission standards are understood to be equal to zero. Equation (3) says that the initial aggregate stock of banked emissions is zero, the aggregate stock of permits may never have negative balances (this constraint is later relaxed to allow borrowing), and at the terminal period the aggregate stock of emission permits is non-negative. Equation (4) requires that firms cannot have negative emission levels.

The joint-cost problem can be solved through use of optimal-control theory. U sing this framework, defining $\Lambda(t)$ as the costate variable on the state equation and $\Phi$ as the multiplier function for the bank non-negativity constraint, the present value $\mathrm{H}$ amiltonian is

$$
H \equiv e^{-r t}\left[\sum_{i=1}^{N} C_{i}(e(t))\right]+\Lambda\left[\sum_{i=1}^{N}\left(S_{i}(t)-e_{i}(t)\right)\right]
$$

and the Lagrangian is

$$
L \equiv e^{-r t}\left[\sum_{i=1}^{N} C_{i}(e(t))\right]+\Lambda\left[\sum_{i=1}^{N}\left(S_{i}(t)-e_{i}(t)\right)\right]-\Phi B .
$$

This problem yields the following necessary conditions for an optimal solution (K amien and Schwartz [6, Part II, Section 17]):

$$
\begin{gathered}
\dot{B}=\frac{\partial L}{\partial \Lambda}=\sum_{i=1}^{N}\left(S_{i}(t)-e_{i}(t)\right) \\
\dot{\Lambda}=-\frac{\partial L}{\partial B}=\Phi ; \quad B \geq 0, \Phi \geq 0, \Phi B=0
\end{gathered}
$$

${ }^{4}$ If both banking and borrowing are always allowed, then (3) and (13) should be replaced with the simpler constraint $B(0)=0$ and $B(T) \geq 0$, rather than $B(0)=0$ and $B(t) \geq 0 \in[0, T]$. 


$$
\begin{gathered}
\frac{\partial L}{\partial e_{i}}=e^{-r t} C_{i}^{\prime}\left(e_{i}\right)-\Lambda \geq 0 ; \quad e_{i} \geq 0, \quad e_{i} \frac{\partial L}{\partial e_{i}}=0, \quad \forall i \\
B(T) \geq 0, \quad-\Lambda(T) \geq 0, \quad B(T) \Lambda(T)=0 .
\end{gathered}
$$

Economic Interpretation of Necessary Conditions for Optimization of the Joint-Cost Problem

Equation (7) simply restates the state equation. N ext, (9) says that all firms that discharge some emissions should have present discounted marginal abatement costs $\left(-e^{-r t} C_{i}^{\prime}\left(e_{i}\right)\right)$ equal to the marginal cost of an additional unit of banked emissions $(-\Lambda)$, and that all firms that discharge emissions should have equal marginal abatement costs. This equation also shows that $\Lambda(t)$, the present value costate variable, which is the marginal or shadow value of a unit of emissions in the bank, is negative. This reflects the fact that if there were an additional unit of emissions in the systemwide bank, systemwide total abatement cost would be lower because firms could then discharge more emissions, which would lower their costs. For later use denote the vector of optimal systemwide emissions from this problem as $\mathbf{E}^{* *}(t)=\left(e_{1}^{* *}(t), \ldots, e_{N}^{* *}(t)\right)$.

Equation (8) says that if, in total, firms bank a positive quantity of emissions over some time interval, then the marginal value of an additional unit of emissions in the systemwide bank is constant for that time interval. This implies that the marginal value of a unit of emission in the bank would always be a negative constant if firms were allowed to borrow emissions (i.e., if $B(t)$ were unrestricted in sign, implying that $\Phi \equiv 0$ ). If firms, in total, would like to borrow emissions, but are not allowed to do so, the marginal value of an additional unit of emissions in the bank would be decreasing (i.e., going to zero from the left since the multiplier, $\Phi(t)$, is positive.

The above conditions tell us what necessary conditions must hold for the minimization of the present value of total costs. The sufficient conditions needed to guarantee an optimum to this problem are that $H$ be convex in $e_{i}$ and $B$ and that the above necessary conditions hold; additional continuity and regularity conditions that are met for this problem are given in full in Theorem 1 of Seierstad and Sydsæter [9, pp. 317, 318]. In particular, the sufficient conditions require that each firm's cost function be convex in emissions. M oreover, existence follows from Theorems 2.1 and 3.1 of Steinberg and Stalford [11], since the state equation (7) is linear in the $e_{i}$, and the integrand is strictly convex in the $e_{i}$.

$\mathrm{N}$ ext, it is necessary to look at how individual firms will make their decisions to optimally control abatement costs and permit purchases and sales, given that firms take permit prices as exogenous.

${ }^{5} \mathrm{~A}$ ccording to Seierstad and Sydsæter, for optimal-control problems with pure state constraints (e.g., $f(B(t), t) \geq 0$, or in this case $B(t) \geq 0$ ), the costate variable may be discontinuous at the terminal period. Given appropriate regularity conditions an optimal solution to the problem still exists, but this possibility will not be considered in the analysis. 


\section{THE FIRM'S PROBLEM}

Formally, defining the optimal value function as $J_{i}^{*}$, and letting $P(t)$ be the instantaneous price of permits $y_{i}(t)$ purchased or sold by firm $i$, and $A_{i}(t)$ and $D_{i}(t)$ be the bounds on the instantaneous purchase and sale of permits, firm $i$ 's problem is

$$
\begin{gathered}
J_{i}^{*} \equiv \operatorname{Min}_{y_{i}, e_{i}} \int_{0}^{T} e^{-r t}\left[C_{i}\left(e_{i}(t)\right)+P(t) y_{i}(t)\right] d t \\
\text { s.t. } \quad \dot{B}_{i}=S_{i}(t)-e_{i}(t)+y_{i}(t) \\
B_{i}(0)=0, \quad B_{i}(t) \geq 0 \\
\quad e_{i}(t) \geq 0 \\
-A_{i}(t) \leq y_{i}(t) \leq D_{i}(t), \quad A_{i}(t)>0, \quad D_{i}(t)>0 .
\end{gathered}
$$

The objective functional (11) says that firm $i$ chooses the level of emissions and purchases or sales of permits to minimize its present discounted costs. Permits may be instantaneously purchased or sold with no transaction costs. Equation (12) is the state equation, which says that changes in the bank of emissions equal the difference between the standard and the level of emission plus any permits bought or sold. Equation (13) says that the initial stock of the bank is zero, firms may never have a negative bank balance (this constraint is later relaxed), and at the terminal period the firm is free to hold any non-negative stocks of emission permits. Equation (14) requires that firms cannot have negative emission levels. Finally, Eq. (15) bounds the instantaneous purchase or sales of permits.

This last constraint, Eq. (15), is a necessary technical requirement that arises if one wants to consider arbitrary price paths, since the objective function is linear in $y_{i}$. The solution to this type of control problem is straightforward but unnecessarily complicated to get at the economic issues at hand. ${ }^{6} \mathrm{~A} n$ alternative approach is to consider price paths for which a solution to the firms problem, without bounds, exists. This is equivalent to assuming that the firm has an internal solution. The economic intuition of this assumption is discussed below. However, there are two cases in which a firm would not have an internal solution. One situation is when the least-cost strategy for the firm is to sell a bounded maximum number of permits at any point in time. The other situation is when a firm's marginal abatement costs are so high that it would rather take no abatement activities, but simply buy as many permits as possible. The maximum number of permits a firm could buy at any point in time is likely to be controlled by the regulatory agency to prevent localized hot spots of concentrated emissions. Thus, in both these cases, a firm could potentially desire to sell, borrow, or buy some maximum number of permits at any point in time.

By assuming that firms do not buy or sell permits at a bounded rate, this problem can be solved through the use of an optimal-control-theory framework by defining $\lambda_{i}(t)$ as the present-value costate variable on the state equation and $\phi_{i}(t)$ as the multiplier function for the bank non-negativity constraint for firm $i$,

\footnotetext{
${ }^{6}$ See Kamien and Schwartz [6, Part II, Section 12] for the solution technique suitable to this problem.
} 
$i=1, \ldots, N .^{7}$ Then, the present-value $\mathrm{H}$ amiltonian is

$$
H_{i}=e^{-r t}\left[C_{i}\left(e_{i}\right)+P y_{i}\right]+\lambda_{i}\left[\left(S_{i}-e_{i}\right)+y_{i}\right] .
$$

The $\mathrm{H}$ amiltonian yields the following necessary conditions: ${ }^{8}$

$$
\begin{gathered}
\dot{B}_{i}=\frac{\partial H_{i}}{\partial \lambda_{i}}=\left(S_{i}-e_{i}\right)+y_{i} \\
\dot{\lambda}_{i}=-\frac{\partial H_{i}}{\partial B_{i}}=\phi_{i} ; \quad B_{i} \geq 0, \phi_{i} \geq 0, \phi_{i} B_{i}=0 \\
\frac{\partial H_{i}}{\partial e_{i}}=e^{-r t} C_{i}^{\prime}\left(e_{i}\right)-\lambda_{i} \geq 0 ; \quad e_{i} \geq 0, e_{i} \frac{\partial H_{i}}{\partial e_{i}}=0 \\
\frac{\partial H_{i}}{\partial y_{i}}=e^{-r t} P+\lambda_{i}=0 \\
B_{i}(T) \geq 0,-\lambda_{i}(T) \geq 0, \quad B_{i}(T) \lambda(T)=0 .
\end{gathered}
$$

\section{Economic Interpretation of the Firm's Necessary Conditions}

Equation (17) simply restates the state equation. Next, looking at Eq. (19), if $\partial H / \partial e_{i}>0$, then $e_{i}=0$ and if $e_{i}>0$, then $-e^{-r t} C^{\prime}\left(e_{i}\right)=-\lambda_{i}$. Thus, if the firm emits some pollution, then the present discounted marginal abatement costs equal the marginal value of an additional unit of emissions in the firm's emission bank account. If present discounted marginal abatement costs (evaluated at the complete abatement level of emissions) are less than the present value of an additional unit of emissions in the bank, then the firm discharges no emissions. Furthermore, $\lambda_{i}$, the marginal value of a unit of banked emissions for firm $i$, is negative. This reflects the fact that if the firm had an additional unit of emissions in the bank, abatement costs would be lower, as would the present value of total costs.

Equation (18) says that the marginal value of a unit of emissions in the bank is increasing (becoming less negative, or smaller in absolute value) if the nonnegativity constraint on the bank is binding. ${ }^{9}$ That is, the value to the firm of an additional unit of emissions in the bank is decreasing if the firm desires to borrow a unit of emissions but it cannot. If the constraint against borrowing were not present, then the marginal value of a unit of banked emissions would be constant whenever the firm was not selling permits at its maximum level.

Looking now at (20), we see that the firm will purchase or sell $y_{i}$ permits so that the discounted marginal cost of a unit in the bank is equal to its discounted price,

\footnotetext{
${ }^{7}$ The more general case requires the introduction of additional multiplier variables for the permit bounds given in (15).

${ }^{8}$ See Seierstad and Sydsæter [9, pp. 332-33] for a complete list of the necessary conditions. "A Imost necessary" conditions basically require that the Lagrangian multiplier, $\phi_{i}$, only has jumps at a finite number of points and has piecewise continuous derivatives elsewhere.

${ }^{9}$ It is also possible for the bank constraint to be binding just enough that the value of a unit of banked emissions is constant and the stock in the bank is equal to zero. This case is not fundamentally different and will not be explicitly addressed.
} 
$e^{-r t} P=-\lambda_{i}$. Permit prices are determined by equilibrium conditions of all firms in the market for permits. For firm $i$ (as well as all other firms) to have a solution without bounds on permit purchases or sales over the entire time horizon, permit prices must follow along a singular path defined by $\alpha \equiv e^{-r t} P+\lambda_{i}=0$. Then, along the singular path, $\dot{\alpha}_{i} \equiv 0$, so the following must hold: $\dot{\alpha}_{i}=-r e^{-r t} P+e^{-r t} P$ $+\dot{\lambda}_{i}=0$. Substituting in for $\dot{\lambda}_{i}$ from Eq. (18), the following equation results: $0=-r e^{-r t} P+e^{-r t} \dot{P}+\phi_{i}$. A fter some manipulation, the following restrictions on the percentage rate of growth in the price of emission permits for the firm to remain on the singular path are derived:

$$
\frac{\dot{P}}{P}=\left\{\begin{array}{c}
r \\
r-\frac{e^{r t} \phi_{i}}{P}
\end{array}\right\} \text { whenever }\left\{\begin{array}{l}
B_{i}>0 \\
\phi_{i}>0
\end{array}\right\} .
$$

If firm $i$ either wants to bank emissions or does not face a restriction on the borrowing of emission credits, then a nonbounded solution requires that the price path of permits follow Hotelling's rule and grow at the rate of return earned from holding any other asset. Equivalently, the present value price of permits, $e^{-r t} P(t)$, is constant. If a firm faces a binding constraint on the borrowing of emission credits, then $\phi_{i}>0$, and the rate of growth in prices must be less than the comparable interest rate. In this case the present-value price of permits is decreasing through time since $e^{-r t} P(t)=-\lambda_{i}(t), \dot{\lambda}_{i}(t)=\phi_{i}(t)>0$, and $\lambda_{i}(t)<0$. Summarizing, for a particular firm to have a non-bounded solution, the present-value price of permits must be constant when each firm can bank and borrow emissions. If the bank is required to be non-negative, and the firm desires to borrow, then a non-bounded solution requires that permit prices be decreasing. The transversality condition, (21), implies that if a firm holds a permit at the terminal period, its value must be zero.

Combining conditions (19) and (20), under the condition that a firm emits a positive quantity of pollution, then $-C_{i}^{\prime}\left(e_{i}\right)=P$. That is, under normal conditions a firm will equate the marginal cost of pollution abatement with the price of a permit. Therefore, present-value marginal abatement costs are constant when each firm can freely bank and borrow emissions, and may decline if borrowing is restricted and firms desire to borrow.

\section{EQUILIBRIUM CONDITIONS}

As discussed above, the regulator's goal is to minimize the joint total costs of pollution abatement of $N$ heterogeneous firms subject to reaching a regional emission standard, $S$, over the $T$-period horizon so that $B(T) \geq 0$. It is necessary to show that an equilibrium in a market for permits exists and is efficient in the sense that it is equal to the system-cost minimization by regulators who know the cost functions of all the firms. M ontgomery's [7] definition of a market equilibrium for pollution permits is used, but modified to account for the dynamic problem at hand.

Especially, but not exclusively, in problems with linear-control variables, the optimal path of the linear control $y_{i}^{*}(t)$ can be discontinuous in $t$. Therefore in Lemma 1, which appears in the Appendix, it is necessary to assume that the 
optimal control $y_{i}^{*}(t)$ is continuous in the price of permits, $P$, even at particular instances, $t=\tau$, where $y_{i}^{*}(t)$ is discontinuous in $t$. This assumption is not too restrictive; its economic content is simply that at a certain point in time if a firm suddenly (e.g., discontinuously) decides to buy or sell a different quantity of permits, the decision is based on a continuous function of the permit price. A $n$ intertemporal equilibrium in the permit market also requires that firms have an internal solution.

DEFINITION. A $n$ intertemporal market equilibrium in emission permits over a $T$ period horizon consists of the vectors $\mathbf{Y}^{*}(t)=\left(y_{1}^{*}(t), \ldots, y_{N}^{*}(t)\right)$ and $\mathbf{E} *(t)=$ $\left(e_{1}^{*}(t), \ldots, e_{N}^{*}(t)\right)$ and the scalar $P^{*}(t) \geq 0$ such that $\mathbf{Y}^{*}(t)$ and $\mathbf{E} *(t)$ minimize each firm's costs given $P^{*}(t)$,

$$
\int_{0}^{T} e^{-r t}\left[C_{i}\left(e_{i}(t)\right)+P^{*}(t) y_{i}(t)\right] d t
$$

subject to each firm's constraints (12)-(15) for each $t \in[0, T]$, and the market clearing condition on permits

$$
\sum_{i=1}^{N} y_{i}^{*}(t)=0 .
$$

The market-clearing condition is a flow condition that simply requires that at any point in time a permit purchased by one firm be sold by some other firm. In addition, cost minimization will also impose the following terminal stock condition:

$$
P^{*}(T)\left[\sum_{i=1}^{N} B_{i}^{*}(T)\right]=0 .
$$

Cost minimization requires that the price of a unit of pollution in the bank be zero at the terminal period or that the stock of permits from all firms be zero.

THEOREM 1. An intertemporal market equilibrium in emission permits over a T-period horizon exists when firms are not buying and selling permits at their maximum instantaneous rate.

Proof. See the A ppendix.

The Market Equilibrium is the Least-Cost Solution

Before proving that the market solution is at least as inexpensive as that from the social planner, it is interesting to think about what banking and borrowing mean in the context of a market. As shown above, the price path of permits must be either constant or decreasing. Thus, for all firms that have not shut down or are not emitting at their maximum rate, $e^{-r t} P(t)=\lambda_{i}(t)$. Thus $\lambda_{i}$ must be equal for all firms and be of either constant or declining value. This says that the value of a unit of banked emission is the same for all firms that have an internal solution for permit purchases, even though it is possible for some firms to borrow while others bank and yet others do neither. F urthermore, if $e^{-r t} P$ is falling over some period, then the result of all firms buying and selling permits is an overall net desire to borrow. 
Now it is necessary to show that the market solution is as least as good as the solution from the social planner. In general, permit prices are some function of all firms' cost functions of emissions abatement, $P=g\left(C_{1}\left(e_{1}\right), \ldots, C_{N}\left(e_{N}\right)\right)$. Given the assumption of interior solutions, (19) and (20) can be equated to yield $C_{i}^{\prime}\left(e_{i}\right)+$ $P(t)=0$. Since $C_{i}^{\prime \prime}>0$, the implicit function theorem implies that $e_{i}=e_{i}(P(t))$ is the solution to this marginal condition, where $\partial E / \partial P(t) \equiv-1 / C_{i}^{\prime \prime}<0$. Over the $T$-period horizon, the total quantity of emissions must be

$$
\int_{0}^{T} \sum_{i=1}^{N} e_{i}\left(P^{*}(z)\right) d z=\int_{0}^{T} \sum_{i=1}^{N} S_{i}(z) d z
$$

since the stock of emissions in the bank is defined to be zero at $t=0$ and will be chosen to be zero at $t=T$.

A $n$ implication of the equilibrium conditions is a relationship between the price path of permits and equilibrium banking. A t any time $t$ the aggregate change in the bank can be expressed as

$$
\dot{B}=\sum_{i=1}^{N} S_{i}(t)-e_{i}(P(t))+y_{i}(P(t)),
$$

and the stock in the bank at any time $t$ equals

$$
B(t)=\int_{0}^{t} \sum_{i=1}^{N}\left(S_{i}(z)-e_{i}(P(z))+y_{i}(P(z))\right) d z .
$$

Given that the permit market clears in each period, this reduces to

$$
B(t)=\int_{0}^{t} \sum_{i=1}^{N}\left(S_{i}(z)-e_{i}(P(z))\right) d z .
$$

This says that the stock of all firms' permits equals the cumulative number of permits that have been banked. If borrowing is allowed, then $B(t)$ can be negative, indicating that, cumulatively, firms are borrowing emissions. When borrowing is not allowed, then it must be non-negative. In either case, over the whole time horizon the sum of all firms' stocks must be non-negative

$$
B(T)=\int_{0}^{T} \sum_{i=1}^{N}\left(S_{i}(z)-e_{i}(P(z))\right) d z \geq 0 .
$$

The last result will be used in the proof that the market-equilibrium solution from firms' individually buying and selling permits is efficient in the sense that it is at least as good as the systemwide cost minimization by regulators who know the cost functions of all firms. This proof is based on a proof by Cronshaw and Kruse [3], who show that a discrete-time permit system with banking attains the minimum joint-cost solution.

THEOREM 2. The market-equilibrium solution $\left(e_{1}^{*}(t), \ldots, e_{N}^{*}(t)\right)$, and $\left(y_{1}^{*}(t), \ldots, y_{N}^{*}(t)\right)$ is at least as inexpensive as the system-cost minimization, so that $\sum_{i=1}^{N} J_{i}^{*} \leq J^{* *}$, where $J^{*}$ and $J^{* *}$ are the optimal-value functions defined in (11) and (1), respectively.

Proof. See the A ppendix. 


\section{CHARACTERIZING THE PATH OF EMISSIONS}

From an environmental perspective, perhaps the most important result of allowing firms to intertemporally move permits, as opposed to simply trading them instantaneously among themselves to attain the least-cost allocation, is the effect that banking and borrowing can have on the stream of emissions through time and the resulting health and environmental impacts. If firms use banking to smooth decreasing emission standards over time and if marginal damages from pollution are increasing, then banking generates lower total pollution damages when considering the integral over the whole time horizon of each period's damage. From the formal model we can derive some insight into how firms adjust their emission streams when they can take advantage of the ability to bank and borrow.

For all firms not buying or selling permits at their maximum rate, but able to equate marginal abatement costs with the marginal value of banked emissions, it was shown earlier that $e^{-r t} C_{i}^{\prime}\left(e_{i}^{*}\right)-\lambda_{i}=0$. If this can be sustained for some nonzero time interval, then along this interval the following condition on the time path of $e_{i}(t)$ is derived by differentiating (25) with respect to $t$ and collecting terms:

$$
\dot{e}_{i}=\frac{r C_{i}^{\prime}\left(e_{i}\right)}{C_{i}^{\prime \prime}\left(e_{i}\right)}+\frac{e^{r} \dot{\lambda_{i}}}{C_{i}^{\prime \prime}\left(e_{i}\right)}
$$

which after substituting from Eq. (18) gives

$$
\dot{e}_{i}=\frac{r C_{i}^{\prime}\left(e_{i}\right)}{C_{i}^{\prime \prime}\left(e_{i}\right)}+\frac{e^{r t} \phi_{i}}{C_{i}^{\prime \prime}\left(e_{i}\right)}
$$

Given the sign conditions described earlier, the first term on the right in (32) is negative and the second term is positive or zero. The second term is zero whenever all the firms desire only to bank emissions or are allowed to borrow emissions. This means that if firms never desire to borrow emissions or desire to borrow and are allowed to do so, so that $\phi_{i}(t)=0$, then the firms' emission streams will decline through time. When borrowing is not allowed and firms desire to borrow, the second term on the right is positive and could be larger in magnitude than the first term, which is negative. Thus, in principle, aggregate emissions could increase through time when borrowing is not allowed. This would occur, however, only when emission standards are becoming less stringent through time.

The discounting of abatement costs causes firms to delay abatement and abatement expenditures beyond the time firms would have engaged in them had costs not been discounted. When standards are constant through time, $\sum_{i=1}^{N} \dot{S}_{i}=0$, then the least-cost behavior of firms is to borrow emissions, $\sum_{i=1}^{N} B_{i}<0$, in early years and pay them back in later years. This is true since, as was shown above, the present-value marginal cost of abatement must be constant when banking and borrowing are allowed. When firms choose to bank emissions, $\sum_{i=1}^{N} B_{i}>0$, it must be because they expect future (undiscounted) abatement costs to rise by more than the rate of discount; they would not otherwise bear the additional earlier abatement expenditures. The only way for undiscounted abatement costs to rise through 
time is for the level of abatement to rise through time, since $-C_{i}^{\prime}\left(e_{i}\right)>0$, $-C_{i}^{\prime \prime}\left(e_{i}\right)>0$. Since constant standards engender borrowing, it must be that banking arises from standards that tighten, $\sum_{i=1}^{N} \dot{S}_{i}<0$, over some interval of time. ${ }^{10}$

If damages from emissions are a convex function and standards are tightening through time, then allowing firms to bank lowers social damages. Banking allows firms to smooth their emission stream through time. For a convex damage function, where cumulative damage is the integral of damages in all time periods, total damages are reduced if the level of emissions is more constant through time. This result is one of the qualitative differences between a static and a dynamic marketable permit system. By giving firms an incentive (cost savings) to more than meet current standards, firms will intertemporally move emissions to lower social damages. This occurs when firms are allowed to bank emissions and when standards are becoming stricter through time. E mission standards' becoming stricter through time is, however, often the norm. If pollution damages are convex, then allowing firms to shift emissions into the present will increase environmental damages. Whether or not firms should be allowed to borrow, at the expense of increasing environmental damages, depends on balancing the cost savings to firms with the additional harm caused by borrowing.

Since firms discount future costs, they will want to borrow when permit prices grow at less than the rate of interest, are constant, or actually decrease over time. In equilibrium, permit prices will equal marginal abatement costs. Thus firms will want to borrow emissions when standards are constant or not becoming more stringent at a sufficiently high rate. H ence, if standards are constant through time so that firms desire to borrow, but are not allowed to do so, then the rate of emissions will remain constant through time. In this case we can give an economically interesting interpretation to $\phi_{i}$, the multiplier on the non-negativity constraint on the bank for firm $i$. Setting $e=0$ in Eq. (32) and rearranging yields $C_{i}^{\prime}\left(e_{i}\right)=-e^{r t} \phi_{i} / r$. Substituting in $-P(t)$ for $C_{i}^{\prime}\left(e_{i}\right)$ and rearranging, it is seen that $\phi_{i}(t)=r e^{-r t} P(t)$. Therefore, $\phi_{i}(t)$, the multiplier on the bank's non-negativity constraint, can be interpreted as the periodic payment that firm $i$ would be willing to make on a perpetual annuity whose purchase price is equal to the present discounted cost of an emission permit.

A special case arises when $r=0$. In this case firms have no incentive to put off costs until the future, and given the assumption of strict convexity of the emissioncontrol function, firms want to emit pollution at the same rate over the entire time horizon, regardless of whether emission standards are becoming stricter. If emission rates are becoming stricter through time and the discount rate is zero, firms will want to save or buy permits in the beginning time periods for later use. Higher discount rates lower the value of future cost savings and decrease the incentive for firms to bank emissions.

This analysis has been framed in a world of certainty. In actuality, marginal abatement costs and marginal damages are uncertain. In particular, a firm might use banked permits to cover a period of particularly high emission levels because of

\footnotetext{
${ }^{10}$ This conclusion needs to be tempered when considering a more general setting than is considered in this model. For example, a firm may wish to bank emissions if investments in abatement equipment are coordinated with other nonabatement investments. Additionally, firms may want to bank emissions in anticipation of future growth, especially when there exists considerable uncertainty about the future price of permits.
} 
a sudden increase in the demand for output. If marginal damages are increasing, this excess burst of emissions could cause unacceptably large damages. A $n$ environmental regulator, therefore, may wish to put a ceiling on the total allowable discharge of emissions in any one given period.

\section{FINAL REMARKS}

This paper characterizes the optimal behavior of firms that face emission standards set by regulators, but are allowed to purchase, sell, bank, and borrow emission permits given a finite planning horizon of length $T$. It was shown that an equilibrium solution to the firms' problems exists and is efficient in the sense of achieving the least-cost solution (the solution attained by a social planner who knows the cost functions of all firms). The equilibrium permit-price path was shown to be constant or decreasing depending on whether firms desired to bank or were allowed to borrow permits and whether firms faced a binding constraint on borrowing. Existence of an equilibrium permit-price path also requires that firms not buy and sell permits at their maximum instantaneous rate. Strategic behavior and price and cost uncertainty were not taken into consideration.

A s argued in the body of the paper, perhaps the most important consequence of emission banking and borrowing is the ability of firms to shift their emission stream through time. In particular, when social damages are an increasing function of the level of pollution emitted at any one time, then it is good public policy to allow firms to bank emissions when standards are becoming stricter through time. In contrast, when standards are constant or easing $(S \geq 0)$, then allowing firms to borrow will raise social damages while lowering firms' costs.

At least for now our society is becoming increasingly concerned with environmental quality, and emission standards are becoming more stringent. This paper has shown that in these circumstances, banking of emission permits can lower social damages. Banking also provides cost savings to firms by allowing them to adjust their own internal rates of emission reductions to an externally set standard. A long with averaging and trading, then, banking can also lower the monetary costs of compliance. Banking, therefore, along with averaging and trading, should be considered by public policymakers in charge of ensuring the safety of our environment.

\section{APPENDIX}

\section{Proof of Theorem 1}

The definitions, lemmas, and proofs that follow are structured after those of M ontgomery [7], who proves the existence of an equilibrium in a permit market for a static problem. The strategy is to derive the sufficient conditions that guarantee a market equilibrium given the market-clearing price $P^{*}(t)$. Next, the sufficient conditions for the existence of a joint-cost minimum are derived and shown to exist. It is then demonstrated that the conditions that satisfy the joint-cost minimum also satisfy the conditions for the market equilibrium where $P^{*}(t)$ is not identified as the negative of the present-value costate variable from the joint-cost problem, i.e., $-e^{r t} \Lambda^{* *}(t)=P^{*}(t)$. 
DEFINITION. A n intertemporal market equilibrium in emission permits over a $T$-period horizon consists of the vectors $\mathbf{Y}^{*}(t)=\left(y_{1}^{*}(t), \ldots, y_{N}^{*}(t)\right)$ and $\mathbf{E}^{*}(t)=$ $\left(e_{1}^{*}(t), \ldots, e_{N}^{*}(t)\right)$ and the scalar $P^{*}(t) \geq 0$ so that $\mathbf{Y}^{*}(t)$ and $\mathbf{E}^{*}(t)$ minimize each firm's costs given $P^{*}(t)$

$$
\int_{0}^{T} e^{-r t}\left[C_{i}\left(e_{i}(t)\right)+P^{*}(t) y_{i}(t)\right] d t
$$

subject to each firm's constraints (11)-(15) for each $t \in[0, T]$, and the marketclearing condition on permits

$$
\sum_{i=1}^{N} y_{i}^{*}(t)=0
$$

The market clearing condition is a flow condition that simply requires that at any point in time a permit purchased by one firm must be sold by some other firm. In addition, cost minimization will also impose the following terminal stock condition:

$$
P^{*}(T)\left[\sum_{i=1}^{N} B_{i}^{*}(T)\right]=0 .
$$

Cost minimization requires that the price of a permit be zero at the terminal period or that the stock of permits from all firms be zero.

L EM MA 1. An intertemporal market equilibrium in emission permits over a T-period horizon exists if there exist optimal shadow values for the emissions for each firm, $\lambda^{*}=\left(\lambda_{1}^{*}(t), \ldots, \lambda_{N}^{*}(t)\right) \geq 0$; non-negativity multipliers for the permit bank, $\phi^{*}=$ $\left(\phi_{1}^{*}, \ldots, \phi_{N}^{*}\right)$; an optimal permit price $P^{*}(t) \geq 0$ for all $t \in[0, T]$, and if, in addition, firms are not buying and selling permits at their maximum instantaneous rate so that

$$
\begin{gathered}
\dot{B}_{i}^{*}=\frac{\partial L_{i}}{\partial \lambda_{i}^{*}}=\left(S_{i}-e_{i}^{*}\right)+y_{i}^{*} \\
\dot{\lambda}_{i}^{*}=-\frac{\partial L_{i}}{\partial B_{i}^{*}}=\phi_{i}^{*} ; \quad B_{i}^{*} \geq 0, \phi_{i}^{*} \geq 0, \phi_{i}^{*} B_{i}^{*}=0 \\
\frac{\partial L_{i}}{\partial e_{i}^{*}}=e^{-r t} C_{i}^{\prime}\left(e_{i}^{*}\right)-\lambda_{i}^{*} \geq 0 ; \quad e_{i}^{*} \geq 0, e_{i}^{*} \frac{\partial L_{i}}{\partial e_{i}^{*}}=0 \\
\frac{\partial L_{i}}{\partial y_{i}}=e^{-r t} P^{*}+\lambda_{i}^{*}=0 \\
B_{i}^{*}(T) \geq 0,-\lambda_{i}^{*}(T) \geq 0, B_{i}^{*}(T) \lambda_{i}^{*}(T)=0
\end{gathered}
$$

and

$$
\sum_{i=1}^{N} y_{i}^{*}(t)=0, \quad P^{*}(T)\left[\sum_{i=1}^{N} B_{i}^{*}(T)\right] .
$$

Proof. This strategy of this proof is to show that firms that minimize costs given $P^{*}(t) \geq 0$ do indeed generate the conditions listed above and that the conditions listed above are sufficient for each firm to minimize costs. 
Form the Lagrangian

$$
L_{i}=e^{-r t}\left[C_{i}\left(e_{i}\right)+P^{*} y_{i}\right]+\lambda_{i}\left[\left(S_{i}-e_{i}\right)+y_{i}\right]-\phi_{i} B_{i} .
$$

For all $i$, the solution $\left(\lambda_{i}^{*}, \phi_{i}^{*}, e_{i}^{*}\right.$, and $y_{i}^{*}$ ) to (A 1$)$ subject to (12)-(15) exists by Theorem 2.1 and 3.1 of Steinberg and Stalford [11]. Moreover, the sufficient conditions of Theorem 3.1 of Seierstad and Sydsæter [9, Chapter 5] are met since the $\mathrm{H}$ amiltonian is convex in $\left(e_{i}, y_{i}, B_{i}\right)$. Differentiation yields the conditions listed above.

DEFINITION. An intertemporal emission-constrained joint-cost minimum over a $T$-period horizon is the vector of emissions $\mathbf{E}^{* *}(t)=\left(e_{i}^{* *}(t), \ldots, e_{N}^{* *}(t)\right)$, which minimizes the joint costs of all firms

$$
J^{* *}(\beta) \equiv \operatorname{Min}_{e_{i}} \int_{0}^{T} e^{-r t} \sum_{i}^{N} C_{i}\left(e_{i}(t)\right) d t
$$

subjet to the constraints for the joint cost problem (2)-(4).

This definition requires the same aggregate level of emission abatement and the same restrictions on the banking of emissions as required by the sum of the abatement activities by each firm in the intertemporal market equilibrium defined above.

The following lemma gives sufficient conditions for the existence of an intertemporal joint-cost minimum to exist. This lemma is then used to prove the existence of an equilibrium in the pollution-permit market.

LEMMA 2. An emission vector $\mathbf{E}^{* *}(t)$ is an intertemporal emission-constrained joint-cost minimum over a T-period horizon if there exist optimal shadow values for the systemwide emissions, $\Lambda^{* *} \geq 0$, and a non-negativity multiplier for the emission bank, $\Phi^{* *} \geq 0$, so that

$$
\begin{gathered}
\dot{B}^{* *}=\frac{\partial L}{\partial \Lambda^{* *}}=\sum_{i=1}^{N}\left(S_{i}-e_{i}^{* *}\right) \\
\dot{\Lambda}^{* *}=-\frac{\partial L}{\partial B^{* *}}=\Phi^{* *} ; \quad B^{* *} \geq 0, \Phi^{* *} \geq 0, \Phi^{* *} B^{* *}=0 \\
\frac{\partial L}{\partial e_{i}}=e^{-r t} C_{i}^{\prime}\left(e_{i}^{* *}\right)-\Lambda^{* *} \geq 0 ; \quad e_{i}^{* *} \geq 0, e_{i}^{* *} \frac{\partial L}{\partial e_{i}}=0, \forall i \\
B^{* *}(T) \geq 0,-\Lambda^{* *}(T) \geq 0, B^{* *}(T) \Lambda^{* *}(T)=0 .
\end{gathered}
$$

Proof. D efining $\Lambda$ as the costate variable on the state equation and $\Phi$ as the multiplier function for the emission bank non-negativity constraint, the Lagrangian for the joint cost minimum is

$$
L \equiv e^{-r t}\left[\sum_{i=1}^{N} C_{i}(e(t))\right]+\Lambda\left[\sum_{i=1}^{N}\left(S_{i}(t)-e_{i}(t)\right)\right]-\Phi B .
$$

$U$ sing the same arguments as in the proof for Lemma 1 , the solution $\left(\Lambda^{* *}, \Phi^{* *}, e_{i}^{* *}\right)$ to (A 11) subject to (1)-(4) exists. 
THEOREM 1. An intertemporal market equilibrium in emission permits over a $T$-period horizon exists when firms are not buying and selling permits at their maximum instantaneous rate.

Proof. This proof proceeds by using the sufficient conditions for the joint-cost problem, (A 12)-(A 15), to show that $e_{i}^{*}=e_{i}^{* *}, y_{i}^{*}=\dot{B}_{i}^{* *}-\left(S_{i}-e_{i}^{* *}\right),-e^{-r t} P^{*}=$ $\Lambda^{* *}$, and $\lambda_{i}^{*}=\Lambda^{* *}$ will also satisfy the sufficient conditions for decentralized problem (A 4)-(A 9) for all $i=1, \ldots, N$ and $t \in[0, T]$.

Equation (A 5). (A 5) is met by setting $\lambda_{i}^{*}=\Lambda^{* *}$ and $\phi_{i}^{*}=\Phi^{* *}$ given in (A 13).

Equation (A 6). From (A 14)

$$
\frac{\partial L}{\partial e_{i}}=e^{-r t} C_{i}^{\prime}\left(e_{i}^{* *}\right)-\Lambda^{* *} \geq 0 ; \quad e_{i}^{* *} \geq 0, e_{i}^{* *} \frac{\partial L}{\partial e_{i}}=0, \forall i .
$$

It is true, therefore, that $e_{i}^{*}=e_{i}^{* *}$ and $\lambda_{i}^{*}=\Lambda^{* *}$ also satisfy (A 6) for all $i$ and $t$. Equation (A 7). Let $\lambda_{i}^{*}=\Lambda^{* *}=-e^{-r t} P^{*}$ for all $i$ and $t$; then (A 7) is satisfied. Equation (A 4). From (A 12) we have

$$
\dot{B}^{* *}=\sum_{i=1}^{N} \dot{B}_{i}^{* *}=\sum_{i=1}^{N}\left(S_{i}-e_{i}^{* *}\right) .
$$

Let $\dot{B}_{i}^{*}=\dot{B}_{i}^{* *}$, and since at $\lambda_{i}^{*}=\Lambda^{* *}=-e^{-r t} P^{*}, e_{i}^{*}=e_{i}^{* *}$, then in addition we know, using (A 4), that

$$
\dot{B}_{i}^{* *}=S_{i}-e_{i}^{* *}+y_{i}^{*}
$$

Summing over all $i$, this gives

$$
\sum_{i=1}^{N} \dot{B}_{i}^{* *}=\dot{B}^{* *}+\sum_{i=1}^{N} y_{i}^{*}
$$

Therefore, $\sum_{i=1}^{N} y_{i}^{*}=0$, which is necessary and feasible. It is also the marketclearing condition.

Equation (A 8). Let $B_{i}^{*}(T)=B_{i}^{* *}(T)$ and $\lambda_{i}^{*}(T)=\Lambda^{* *}(T)$. Let no firm hold any stock of pollutants in the joint-cost problem at $t=T$; then $\sum_{i=1}^{N} B_{i}^{* *}(T)=$ $B^{* *}(T)=0$. By setting $B_{i}^{*}(T)=B_{i}^{* *}(T)=0$ we have a feasible solution that satisfies the equality requirement of (A 8). Now let only one firm, firm $i$, hold a stock of permits at $t=T$. Then $\sum_{i=1}^{N} B_{i}^{* *}(T)>0$. Letting $B_{i}^{*}(T)=B_{i}^{* *}(T)$, we have a feasible solution that satisfies the inequality part of (A 8). In addition, let $P^{*}(T)=\Lambda^{* *}(T)$, and we get the cost-minimizing condition on the terminal-period stock, which requires that $P^{*}(T)\left[\sum_{i=1}^{N} B_{i}^{*}(T)\right]=0$. Therefore, we have found a feasible solution that exists and satisfies all the conditions of Lemma 1.

Proof of Theorem $2{ }^{11} \quad$ Let $e_{i}^{*}(t)$ and $y_{i}^{*}(t)$ be the cost-minimizing emission and permit paths for firm $i$. Suppose, however, that $e_{i}^{*}(t)$ and $y_{i}^{*}(t)$ do not minimize the system costs. Then there exist some other $\tilde{e}_{i}(t)$ and $\tilde{y}_{i}(t)$ that are feasible and

\footnotetext{
${ }^{11}$ This proof is a continuous-time adaptation of a proof by Cronshaw and Kruse.
} 
produce a lower system cost. That is,

$$
\begin{gathered}
\int_{0}^{T} \sum_{i=1}^{N} \tilde{e}_{i}(z) d z \leq \int_{0}^{T} \sum_{i=1}^{N} S_{i}(z) d z \quad \text { (feasibility), } \\
\int_{0}^{T} \sum_{i=1}^{N} e^{-r t} C_{i}\left(\tilde{e}_{i}(z)\right) d z<\int_{0}^{T} \sum_{i=1}^{N} e^{-r t} C_{i}\left(e_{i}^{*}(z)\right) d z \quad \text { (lower cost). }
\end{gathered}
$$

Now, defining alternative permit purchases and sales so that the first $N-1$ firms have enough permits for their emissions and so that the permit market clears

$$
\tilde{y}_{i}=\left\{\begin{array}{ll}
\tilde{e}_{i}-S_{i} & \text { for } i=1, \ldots, N-1 \\
-\sum_{j=1}^{N-1} \tilde{y}_{j} & \text { for } i=N
\end{array}\right\} .
$$

In addition, from (A 19), firm $N$ also has a sufficient initial endowment and permits to cover its emissions

$$
\int_{0}^{T}\left(\tilde{y}_{N}(z)+S_{N}-\tilde{e}_{N}(z)\right) d z=\int_{0}^{T} \sum_{i=1}^{N}\left(\tilde{S}_{i}-\tilde{e}_{i}(z)\right) d z \geq 0 .
$$

Since $\sum_{i=1}^{N} y_{i}=0$, then $\sum_{i=1}^{N} P y_{i}=0$ because $P(t)$ is the same for all firms. Therefore, upon using the last observations in (A 18) and (A 19), the cost of the alternative program is less than that of the equilibrium,

$$
\int_{0}^{T} \sum_{i=1}^{N}\left(e^{-r t}\left[C_{i}\left(\tilde{e}_{i}(z)\right)+P \tilde{y}_{i}(z)\right]\right) d z<\int_{0}^{T} \sum_{i=1}^{N}\left(e^{-r t}\left[C_{i}\left(e_{i}^{*}(z)\right)+P y_{i}^{*}(z)\right]\right) d z
$$

So for some firm $i$, it must be true that

$$
\int_{0}^{T}\left(e^{-r t}\left[C_{i}\left(\tilde{e}_{i}(z)+P \tilde{y}_{i}(z)\right)\right]\right)<\int_{0}^{T}\left(e^{-r t}\left[C_{i}\left(e_{i}^{*}(z)\right)+P y_{i}^{*}(z)\right]\right) d z,
$$

but this contradicts the optimality of $e_{i}^{*}(t)$ and $y_{i}^{*}(t)$ for the firm. This proves that the market equilibrium is efficient.

\section{REFERENCES}

1. California Air Resources Board, "Proposed Regulations for Low-Emission Vehicles and Clean Fuels," staff report, A ugust 1990.

2. "Congressional Quarterly 1980 A Imanac," Congressional Quarterly Inc., Washington, D.C. (1981).

3. M ark B. Cronshaw and Jamie B. Kruse, "Permit M arkets with Banking," working paper, Dept. of E conomics, U niversity of Colorado, B oulder (1993).

4. M aureen Cropper and Wallace O ates (1992), Environmental economics: A survey, J. Econ. Lit. 30, 675-740 (1992).

5. J. H. Dales, "Pollution, Property, and Prices," U niversity of Toronto Press, Toronto, Canada (1968).

6. M orton I. Kamien, and N ancy L. Schwartz, "D ynamic O ptimization: The Calculus of $V$ ariations and O ptimal Control in Economics and M anagement," Second E dition, Elsevier, N ew Y ork (1991).

7. David W. Montgomery, Markets in licenses and efficient pollution control programs, J. Econ. Theory 5, 395-418 (1972). 
8. J onathan R ubin and Catherine K ling, A n emission saved is an emission earned: A n empirical study of emission banking for light-duty vehicle manufacturers, J. Environ. Econom. Manag. 25(3), 257-74 (1993).

9. A tle Seierstad and Knut Sydsæter, "Optimal Control Theory with Economic Applications," (Advanced Textbooks in E conomics, 24) Elsevier, N ew Y ork (1987).

10. Brian Shaffer, Regulation, competition, and strategy: The case of automobile fuel economy standards, 1974-1991, Markets, Politics and Social Perform., 13, 191-218 (1992).

11. A. M. Steinberg and H. L. Stalford, On existence of optimal controls, J. Optim. Th. Appl. 11(3) 267-273 (1973).

12. Thomas Tietenberg, "E mission Trading, A n Exercise in R eforming Pollution Policy," R esources for the Future, W ashington, D.C. (1985). 